\title{
APPLICATION OF AQUEOUS TWO PHASE SYSTEMS BASED ON POLYETHYLENE GLYCOL AND SODIUM CITRATE FOR THE RECOVERY OF PHENOLIC COMPOUNDS FROM EUCALYPTUS WOOD
}

\author{
Lucía Xavier', María Sonia Freire ${ }^{1}$, Isabel Vidal-Tato ${ }^{1}$, Julia González-Álvarez ${ }^{1, \AA}$
}

\begin{abstract}
This paper proposes an alternative way to intensify the exploitation of Eucalyptus wood wastes before valorisation for energy production. An aqueous two-phase system (ATPS) based on PEG 2000 and sodium citrate was investigated for the recovery of phenolic compounds that could act as natural antioxidants for applications including cosmetics, pharmaceuticals, food additives and other industrial applications. The influence of the tie line length (TLL) $(26,1-46,1 \%)$, extraction temperature $\left(25-65^{\circ} \mathrm{C}\right)$, extraction time $(90-390$ $\mathrm{min})$ and phase settlement time (1-8 h) were studied. Phenolic compounds were concentrated preferentially in the PEG-rich phase. A partition coefficient of 38 and a total phenols yield of $1,29 \mathrm{mg}$ gallic acid equivalent $/ 100$ mg wood dry basis were obtained under the operational conditions selected: TLL, $46,1 \%$, temperature $65^{\circ} \mathrm{C}$, extraction time $90 \mathrm{~min}$ and settlement time $1 \mathrm{~h}$. Analysis of the extracts by RP-HPLC-ESI-TOF confirmed the presence of various phenolic compounds with demonstrated antioxidant activity: monogalloyl glucose, (-)-gallic acid, ellagic acid and quercetin 3-O-rhamnoside.
\end{abstract}

Keywords: Aqueous two-phase systems, biomass wastes, Eucalyptus wood, natural antioxidants, polyethylene glycol, sodium citrate.

\section{INTRODUCTION}

As of late, much attention is being paid to the exploitation of biomass residues. Generally, these residues are burnt for power generation. However, alternative uses to extract valuable compounds such as phenolic compounds for use as natural antioxidants in applications including cosmetics, pharmaceuticals, food additives and other industrial applications should be explored.

Antioxidants are a group of chemical derivatives that extend the shelf-life of different products, such as food or cosmetics, by protecting them against deterioration caused by oxidation. Extraction is a common method for the isolation of natural antioxidants and it is mainly performed with organic solvents (Vázquez et al. 2008, Aspé and Fernández 2011, Fernández-Agulló et al. 2013, Ramos et al. 2013). Although this procedure is efficient and solvents such as ethanol are GRAS (generally recognized as safe), the extracts from other solvents are generally not safe for human consumption due to potentially toxic effects of residual solvents (Salic et al. 2011). Therefore, solvent selection is an important variable.

One of the goals of green chemistry and engineering is to develop alternative ways of extraction which not do involve organic solvents. Aqueous two-phase extraction (ATPE) is a powerful method for extraction and purification of biomolecules that has numerous advantages over conventional solvent extraction (Benavides and Rito-Palomares 2008). The major benefits are high capacity, biocompatible environment, low interfacial tension of phases, high yields, short process time and low energy consumption (Chethana et al. 2007).

\footnotetext{
${ }^{1}$ Department of Chemical Engineering, School of Engineering, University of Santiago de Compostela,15782 Santiago de Compostela, Spain. ^Corresponding author: julia.gonzalez@usc.es Received: 14.01.2014 Accepted: 18.07.2014
} 
There are two main types of aqueous two phase systems (ATPS): polymer-polymer and polymersalt systems (Albertsson 1986, Benavides and Rito-Palomares 2008). Polymer-salt systems have several advantages; namely: low price, low viscosity and short time for phase separation, among others (Peng et al. 1994, Benavides and Rito-Palomares 2008, Wang et al. 2008, Khayati et al. 2011). For this type of ATPS, using polyethylene glycol (PEG) as the polymeric component has many environmental advantages, being nontoxic, non-inflammable and biodegradable (Chen et al. 2005, Khayati et al. 2011). With respect to the salt component, citrate has been used to form ATPS with PEG. This is due to the fact that citrates are biodegradable and nontoxic and, consequently, PEG/citrate salts can form environmentally safe ATPS, which are suitable for the extraction of biological materials (Murugesan and Perumalsamy 2005).

ATPS have been used in bioseparation for nearly fifty years. Many researchers studied various applications of ATPS for the extraction and purification of biological products (Benavides and Rito-Palomares 2008, Aguilar and Rito-Palomares 2010, Ratanapongleka 2010). Despite many recent studies on the subject, there is still no extensive information about extraction of natural antioxidants with this technique and direct application over raw materials (Hassman et al. 2008, Wang et al. 2008, Wu et al. 2011, Xavier et al. 2013).

The aim of this paper was to find an efficient way of valorizing a waste material from the wood industry: trimmings of Eucalyptus wood veneers used for the finishing of wood panels, which are produced in high amounts ( $30 \%$ of the processed veneers). The objective was the recovery of phenolic compounds that could act as natural antioxidants before valorization for energy production. For it, ATPS (water+polymer+salt) based on PEG 2000 and sodium citrate were investigated in detail and the influence of the tie line length, extraction temperature, extraction time and phase settlement time was analyzed.

\section{MATERIALS AND METHODS}

\section{Raw Material}

Eucalyptus (Eucalyptus globulus) wood veneer trimmings were supplied by the company Aserpal S.A. (Grupo Losán S.A., Galicia, NW Spain). Veneers were obtained from slicing a block of Eucalyptus wood lengthways, which was previously pretreated in water at $75^{\circ} \mathrm{C}$ for $16 \mathrm{~h}$. Then, in the laboratory, the veneer trimmings were air-dried till equilibrium humidity and prepared in pieces of $0,60 \mathrm{~mm} \times 10 \mathrm{~mm} \times 20 \mathrm{~mm}$.

\section{Chemicals}

Sodium carbonate, tri-sodium citrate di-hydrated, gallic acid-1-hydrate, and Folin-Ciocalteu's phenol reagent were purchased from Panreac (Barcelona, Spain). Acetic acid, acetonitrile and polyethylene glycol (PEG) 2000 from Merck (Darmstadt, Germany). HPLC standards: (+)-catechin hydrate, (-)-epicatechin, procyanidin B2, quercetin-3- $\beta$-D glucoside, quercetin-3-O-rhamnoside, ellagic acid, isorhamnetin, kaempferol and tannic acid were purchased from Fluka (Steinheim, Germany); gallocatechin was from Sigma (Steinheim, Germany) and (-)-gallic acid was from Riedel-de Haën (Seelze, Germany).

\section{Extraction and separation procedure}

The aqueous two-phase systems (water + polymer + salt) based on PEG 2000 and sodium citrate were prepared using the phase diagram of the ternary system found in literature (Murugesan and Perumalsamy 2005). 
A predetermined quantity of sodium citrate was dissolved in water and the $\mathrm{pH}$ was measured. Afterwards, in order to form the ATPS, the corresponding quantity of PEG according to the composition selected (Table 1) was added to the sodium citrate solution with a $\mathrm{pH}$ of 9,1 . Finally, the biomass $(5,0 \mathrm{~g})$ was added. The extractions were performed in a water bath with orbital shaking (UNITRONIC-OR, Selecta, Spain) at a shaking rate of $90 \mathrm{rpm}$. The variables examined were: temperature $\left(25,45\right.$ and $\left.65^{\circ} \mathrm{C}\right)$, extraction time $(90$, 210, 270, 330 and $390 \mathrm{~min}$ ) and three different tie line lengths (TLL) (26,1, 40,4 and 46,1\%). The amount of liquid used in the extraction process was $50 \mathrm{~g}$ and the solid/liquid ratio was maintained at $1 / 10(\mathrm{w} / \mathrm{w})$. After the extraction, the wood pieces were removed and the phases were gravity separated. Afterwards, the total phenols content was determined. In order to establish the settlement time, the separation was performed at different times $(1$ and $8 \mathrm{~h})$. All experiments were carried out in triplicate.

Table 1. Composition data for aqueous two-phase systems based on PEG 2000 and sodium citrate.

\begin{tabular}{ccccc}
\hline & $\begin{array}{c}\text { PEG 2000 } \\
\text { System }\end{array}$ & $\begin{array}{c}\mathrm{Na}_{3} \mathrm{C}_{6} \mathrm{H}_{5} \mathrm{O}_{7} \\
(\%)\end{array}$ & $\begin{array}{c}\mathrm{H}_{2} \mathrm{O} \\
(\%)\end{array}$ & $\begin{array}{c}\text { TLL } \\
(\%)\end{array}$ \\
\hline 1 & 15,48 & 13,64 & 70,88 & 26,1 \\
2 & 18,50 & 15,14 & 66,36 & 40,4 \\
3 & 20,02 & 15,96 & 64,02 & 46,1 \\
\hline
\end{tabular}

(\% by weight)

\section{Total phenols content}

Total phenols content was determined by the Folin-Ciocalteu method (Singleton and Rossi 1965): to 0,5 $\mathrm{mL}$ of an aqueous extract solution, $2,5 \mathrm{~mL}$ of Folin-Ciocalteu reagent previously diluted with water $(1: 10, \mathrm{v} / \mathrm{v})$ and $2 \mathrm{~mL}$ of a $75 \mathrm{~g} / \mathrm{L}$ sodium carbonate aqueous solution were added. The mixture was kept for $5 \mathrm{~min}$ at $50^{\circ} \mathrm{C}$ and, after cooling, the absorbance was measured at $760 \mathrm{~nm}$ in a Jasco V-530 UV-visible spectrophotometer. The phenols content was calculated as gallic acid equivalent (GAE) from the calibration curve of gallic acid standard solutions $(2-40 \mathrm{mg} / \mathrm{mL})$. The results were expressed as total phenols concentration $(\mathrm{mg}$ GAE/L) and as total phenols yield (mg GAE/100 mg of oven-dried (o.d.) wood), which takes into account both the amount $(\mathrm{g})$ and the phenols concentration of each phase. All analysis were carried out in triplicate.

\section{RP-HPLC-ESI-TOF mass spectrometry analysis}

The top PEG-rich phase of selected samples, once separated from the bottom phase as previously indicated, was lyophilized in a ScanVac Coolsafe 100-9PRO lyophilizer (LaboGene, Denmark). The lyophilized sample was analyzed for its phenolic composition by RP-HPLC-ESI-TOF using an HPLC Agilent Technologies 1100 (Agilent Technologies, Germany) and the Bruker Microtof ESI-TOF analyzer (Bruker Daltonics, Germany).

Phenolic compounds were separated using a Zorbax Eclipse XDB-C18 4,6 x $150 \mathrm{~mm}, 5 \mu \mathrm{m}$ column (Agilent Technologies, Germany). A binary gradient of $2 \%$ aqueous acetic acid for mobile phase A and 0,5\% acetic acid in water-acetonitrile (1:1, v:v) for mobile phase B at a flow rate of $1 \mathrm{ml} / \mathrm{min}$ was applied. The linear gradient was from 10 to $55 \%$ B for the time range from 0 to $50 \mathrm{~min}$, from 55 to $100 \%$ B from 50 to 60 min and from 100 to $10 \%$ B from 60 to $65 \mathrm{~min}$. The mass spectrometry analysis was performed in negative ion mode under the following conditions: analyzer TOF (time-of-flight), ionization source ESI (electrospray), capillary voltage at $+4,5 \mathrm{kV}$, nebulizer gas pressure at $32 \mathrm{psi}$, dry gas flow at $12 \mathrm{~L} / \mathrm{min}$, injection volume $10 \mu \mathrm{l}$. The sample and the standards were dissolved in water to a concentration in the range $100-200 \mathrm{ppm}$.

\section{Statistical analysis}

Data were reported as mean \pm SD (standard deviation) of triplicate determinations. The existence of significant differences among the results for total phenols concentration and total phenols yield depending on the extraction conditions was analysed. For it, one-way analysis of variance (ANOVA) was used followed by the Tukey's HSD or Dunnett T3 test, depending on whether equal variances could be assumed or not. All statistical tests were performed at a 5\% significance level using PASW Statistics 18 software. 


\section{RESULTS AND DISCUSSION}

The recovery of phenolic compounds from eucalyptus wood wastes using aqueous two-phase systems based on PEG 2000 and sodium citrate was studied. Given an ATP system, operational variables such as temperature, TLL polymer and salt concentrations are usually considered to have significant effect on the extraction process (Benavides and Rito-Palomares 2008). In this work, the influence of TLL, temperature and extraction time on phenols recovery was analyzed sequentially and, in each phase the best value of the corresponding variable was selected to continue experimentation. Additionally, the influence of the settlement time ( 1 or $8 \mathrm{~h})$ was studied first at fixed values of the rest of the variables to guarantee that equilibrium was reached.

The partition coefficient $\left(\mathrm{K}_{\mathrm{p}}\right)$ of phenolic compounds was calculated as the ratio of the total phenol concentration in the top phase to that in the bottom (both in $\mathrm{mg} \mathrm{GAE} / \mathrm{L}$ ). In addition, to take into account the changes in the volume ratio of both phases $\left(\mathrm{V}_{\mathrm{r}}=\right.$ volume top phase/volume bottom phase), a recovery coefficient $(\mathrm{Y})$ was calculated as the ratio of the total phenols in the top phase to the total phenols extracted in both phases (both in mg GAE).

\section{Phenols partition}

The total phenols yield was higher on the top phase (TP) than on the bottom phase (BP), indicating that phenolic compounds were concentrated preferentially in the PEG-rich phase (Table 2-5). In addition, both the partition coefficient $\left(\mathrm{K}_{\mathrm{p}}\right)$ and the recovery coefficient $(\mathrm{Y})$ were high in all systems and operational conditions essayed (Tables 2-5). It is well known that phenols prefer the polymer-rich phase. This phenomenon can be explained considering several effect including hydrophobic and hydrogen bond interaction between phenolic compounds, PEG phase-forming components, the exclusion volume, the salting out effect and the polarity (Willauer et al. 2000, Shen et al. 2006, Chavez-Santoscoy et al. 2010, Salic et al. 2011). Xavier et al. (2013) have also reported that using ATPS based on PEG 2000 and ammonium sulphate phenolic compounds preferred the polymer-rich phase with high partition coefficients.

\section{Influence of settlement time on phenol recovery}

After the extraction stage the systems were allowed to settle, to ensure proper phase separation and equilibrium reached. To guarantee that equilibrium was reached, the two formed phases were separated under gravity using two different settlement times and maintaining the rest of the variables at fixed values (Table 2).

The total phenols concentration of the top phase varied between $2979 \pm 243 \mathrm{mg} \mathrm{GAE} / \mathrm{L}$ for a settlement time of $1 \mathrm{~h}$ and $2861 \pm 124 \mathrm{mg}$ GAE/L for $8 \mathrm{~h}$, without significant differences between them. Moreover, the partition coefficient was almost the same in both experiments. This means that the equilibrium was reached quickly; as a consequence, a settlement time of $1 \mathrm{~h}$ was selected for the rest of the experiments.

Table 2. Influence of the settlement time on the recovery of phenolics from Eucalyptus wood veneers (TLL, 46,1\%; extraction time, $90 \mathrm{~min}$; extraction temperature, $45^{\circ} \mathrm{C}$; $\mathrm{Vr}, 0,7$ ).

\begin{tabular}{|c|c|c|c|}
\hline $\begin{array}{l}\text { Settlement } \\
\text { time } \\
\text { (h) }\end{array}$ & $\begin{array}{c}\text { Total phenols } \\
\text { concentration } \\
\text { TP } \\
(\mathrm{mg} \mathrm{GAE} / \mathrm{L})\end{array}$ & $\begin{array}{c}\text { Total phenols } \\
\text { concentration } \\
\text { BP } \\
(\mathrm{mg} \mathrm{GAE} / \mathrm{L})\end{array}$ & $\begin{array}{c}\mathrm{K}_{\mathrm{p}} \\
\text { (mg GAE/L TP/ } \\
\text { mg GAE/L BP) }\end{array}$ \\
\hline 1 & $2979 \pm 243^{a}$ & $55,8 \pm 4,6^{\mathrm{a}}$ & $53,7 \pm 6,9$ \\
\hline 8 & $2861 \pm 124^{\mathrm{a}}$ & $50,5 \pm 3,7^{\mathrm{a}}$ & $56,8 \pm 1,7$ \\
\hline
\end{tabular}




\section{Effect of the tie line length on phenol recovery}

The TLL relates the mass ratio between phases in equilibrium (Salic et al. 2011). Many researchers have suggested that TTL may have an influence on recovery (Benavides and Rito-Palomares 2008, Salic et al. 2011). In order to examine the effect of the TLL on phenols recovery from the top phase, experiments were performed using three different TLL ordered as TLLs ystem $3_{3}>\mathrm{TLL}_{\text {system } 2}>\mathrm{TLL}_{\text {system 1 }}$. Temperature, extraction time, $\mathrm{pH}$, solid-liquid ratio, settlement time and volume ratio of both phases were kept constant.

As seen from table 3, no significant differences among total phenols yields in the top phase were observed. However, the highest value was found for systems 1 and 3, and the latter with a higher partition coefficient. As a consequence, system 3 was chosen to continue experimentation.

In fact, system 3 had the highest salt concentration on the bottom phase and the highest PEG concentration on the top phase. On one hand, the high concentration of citrate in the bottom phase induces the migration of compounds to the top phase by the salting out effect. On the other, the high PEG concentration on the top phase could increase hydrophobic characteristics of the phase and increases the effect of exclusion volume (Shen et al. 2006, Willauer et al. 2000).

Table 3. Effect of tie line length on total phenols yield and partition coefficient (extraction time, 90 min; extraction temperature, $65^{\circ} \mathrm{C}$; settlement time, $1 \mathrm{~h}$; $\left.\mathrm{Vr}, 0,5\right)$.

\begin{tabular}{|c|c|c|c|}
\hline System & $\begin{array}{c}\text { Total phenols } \\
\text { yield, TP } \\
\text { (mg GAE/ } \\
100 \text { mg o.d. wood) }\end{array}$ & $\begin{array}{c}\text { Total phenols } \\
\text { yield, BP } \\
\text { (mg GAE/ } \\
100 \text { mg o.d. wood) }\end{array}$ & $\begin{array}{c}\mathrm{K}_{\mathrm{p}} \\
(\mathrm{mg} \mathrm{GAE} / \mathrm{L} \mathrm{TP} / \\
\mathrm{mg} \mathrm{GAE} / \mathrm{L} \mathrm{BP})\end{array}$ \\
\hline 1 & $1,29^{\mathrm{a}} \pm 0,14$ & $0,084^{\mathrm{a}} \pm 0,008$ & $31,5 \pm 2,2$ \\
\hline 2 & $1,21^{\mathrm{a}} \pm 0,07$ & $0,052^{b c} \pm 0,001$ & $46,7 \pm 5,0$ \\
\hline 3 & $1,29^{\mathrm{a}} \pm 0,02$ & $0,064^{\mathrm{c}} \pm 0,002$ & $38,0 \pm 0,8$ \\
\hline
\end{tabular}

\section{Effect of temperature}

The phase equilibrium for an aqueous two phase system is generally influenced by temperature (Voros et al. 1993, Willauer et al. 2000, Salic et al. 2011). For PEG-sodium citrate ATPS, an increase in temperature causes an increase in the length of the tie line, and moreover an increase in the slope of the equilibrium tie lines (Murugesan and Perumalsamy 2005). As a result, the polymer concentration on the upper phase increases, while the lower phase in equilibrium is more diluted. This causes a significant change in the compositions of the phases in equilibrium This trend can be observed in Table $4, V_{r}$ decreases as temperature increases.

As shown in Table 4, the highest total phenols yield on the top phase was obtained at the highest temperature essayed $65^{\circ} \mathrm{C}, 1,29 \pm 0,02 \mathrm{mg} \mathrm{GAE} / 100 \mathrm{mg}$ o.d. wood, whereas at $25^{\circ} \mathrm{C}$, the lowest phenols yield was attained, $0,76 \pm 0,09 \mathrm{mg} \mathrm{GAE} / 100 \mathrm{mg}$ o.d. The same trend was observed on the bottom phase. The increase of temperature resulted in most cases in an increase of diffusion rate and solubility of the extracted substances (Jokic et al. 2010). On the other hand, temperature had no influence on the recovery yield (Y), which hardly varied with temperature. That is, system selectivity is temperature-invariant. However, it should be noticed that the partition coefficient $\left(\mathrm{K}_{\mathrm{p}}\right)$ decreased with increasing temperature (Table 4). This can be explained by the increase in $V_{r}$ when temperature diminishes, and the consequent changes in phase concentrations. In view of the results obtained the following experiments were conducted at $65^{\circ} \mathrm{C}$. 
Table 4. Influence of temperature on the extraction of phenolics from Eucalyptus wood veneers (TLL, 46,1\%; S/L 1:10; extraction time, 90 min; settlement time, 1 h).

\begin{tabular}{|c|c|c|c|c|c|}
\hline $\begin{array}{c}\text { Temperature } \\
\left({ }^{\circ} \mathrm{C}\right)\end{array}$ & $\begin{array}{c}\text { Total } \\
\text { phenols } \\
\text { yield, TP } \\
\text { (mg GAE/ } \\
100 \mathrm{mg} \\
\text { o.d. wood) }\end{array}$ & $\begin{array}{c}\text { Total } \\
\text { phenols } \\
\text { yield, BP } \\
\text { (mg GAE/ } \\
100 \mathrm{mg} \\
\text { o.d. wood) }\end{array}$ & $\begin{array}{c}\mathrm{V}_{\mathrm{r}} \\
(\mathrm{mL} \mathrm{TP/} \\
\mathrm{mL} \mathrm{BP})\end{array}$ & $\begin{array}{c}\mathrm{K}_{\mathrm{p}} \\
\text { (mg GAE/L } \\
\mathrm{TP} / \\
\text { mg GAE/L BP) }\end{array}$ & $\begin{array}{c}\mathrm{Y} \\
\text { (mg GAE } \\
\text { TP/ } 100 \mathrm{mg} \\
\text { extracted) }\end{array}$ \\
\hline 25 & $0,76^{\mathrm{a}} \pm 0,09$ & $0,010^{\mathrm{a}} \pm 0,000$ & $0,9 \pm 0,1$ & $91,8 \pm 5,4$ & $98,7 \pm 0,2$ \\
\hline 45 & $0,96^{\mathrm{b}} \pm 0,04$ & $0,028^{\mathrm{b}} \pm 0,002$ & $0,7 \pm 0,0$ & $53,7 \pm 6,9$ & $97,2 \pm 0,2$ \\
\hline 65 & $1,29^{c} \pm 0,02$ & $0,064^{\mathrm{c}} \pm 0,002$ & $0,5 \pm 0,0$ & $38,0 \pm 0,8$ & $95,3 \pm 0,0$ \\
\hline
\end{tabular}

TP, top phase ; BP, bottom phase

Values are presented as mean $\pm \mathrm{SD}(\mathrm{n}=3)$. In each column, values with different letters are significantly different $(\mathrm{p}<0,05)$

\section{Effect of extraction time on recovery}

The recovery of phenolic compounds can be extraction time-dependent. Then, as the last stage, the impact of extraction time on total phenols yield was investigated. The highest value of total phenols yield in the top phase was obtained at $270 \mathrm{~min}$, however, there were no significant differences among the results obtained at all extraction times essayed (Table 5). Moreover, the partition coefficient decreased slightly with increasing extraction time. Therefore, an extraction time of $90 \mathrm{~min}$ was choosen for the recovery of phenolic compounds from eucalyptus wood using a PEG-sodium citrate ATPS under the previously selected conditions for the rest of the variables.

Finally, the results obtained were compared with those previously achieved for PEG 2000-amonium sulphate ATPS (Xavier et al. 2013) operating under the same ranges of S/L ratio, temperature and extraction time. The total phenolic yield in the PEG-rich phase was notably higher for the PEG 2000-citrate systems (0,76-1,70 mg GAE/100 mg o.d.wood) than for the PEG 2000-amonium sulphate systems $(0,69-1,32 \mathrm{mg}$ GAE/100 mg o.d. wood).

Table 5. Influence of extraction time on the extraction of phenolics from Eucalyptus wood veneers (TLL, 46,1\%; extraction temperature, $65^{\circ} \mathrm{C}$; settlement time, $1 \mathrm{~h} ; \mathrm{V}_{\mathrm{r}}=0,5$ ).

\begin{tabular}{cccc}
\hline $\begin{array}{c}\text { Extraction } \\
\text { time } \\
(\mathrm{min})\end{array}$ & $\begin{array}{c}\text { Total phenols } \\
\text { yield, TP } \\
\text { (mg GAE/ } \\
100 \text { mg o.d.wood) }\end{array}$ & $\begin{array}{c}\text { Total phenols } \\
\text { Yield, BP } \\
\text { (mg GAE/ } \\
100 \text { mg o.d. wood) }\end{array}$ & $\begin{array}{c}\mathrm{K}_{\mathrm{p}} \\
\text { (mg GAE/LTP/ } \\
\text { mg GAE/L BP) }\end{array}$ \\
\hline 90 & $1,29^{\mathrm{a}} \pm 0,02$ & $0,0635^{\mathrm{a}} \pm 0,0019$ & $38,0 \pm 0,8$ \\
210 & $1,51^{\mathrm{a}} \pm 0,13$ & $0,0887^{\mathrm{a}} \pm 0,0063$ & $37,1 \pm 0,5$ \\
270 & $1,70^{\mathrm{a}} \pm 0,22$ & $0,0982^{\mathrm{a}} \pm 0,0088$ & $37,6 \pm 4,1$ \\
330 & $1,61^{\mathrm{a}} \pm 0,10$ & $0,1091^{\mathrm{a}} \pm 0,0006$ & $34,0 \pm 4,1$ \\
390 & $1,67^{\mathrm{a}} \pm 0,23$ & $0,1100^{\mathrm{a}} \pm 0,0033$ & $32,6 \pm 3,3$ \\
\hline
\end{tabular}

TP, top phase ; BP, bottom phase

Values are presented as mean $\pm \mathrm{SD}(\mathrm{n}=3)$. In each column, values with different letters are significantly different $(\mathrm{p}<0,05)$ 


\section{RP-HPLC-ESI-TOF mass spectrometry results}

Figure 1 shows the HPLC chromatogram of the top-phase eucalyptus wood extract obtained under the operational conditions previuosly selected: settlement time $1 \mathrm{~h}$, system 3 , extraction temperature $65^{\circ} \mathrm{C}$ and extraction time $90 \mathrm{~min}$.

The following phenolic compounds were identified based on the retention time of standard compounds: monogalloyl glucose (peak 3), (-)-gallic acid (peak 4), ellagic acid (peak 12) and quercetin 3-O-rhamnoside (peak 13) (Table 6, Figure 1). All these compounds typically occur in bark, leaves or needles of eucalyptus sp. (Conde et al. 1996, Eyles et al. 2003). The same phenolic compounds were also found in Eucalyptus wood extracts obtained using PEG 2000-amonium sulphate ATPS and ellagic acid was also the more abundant one (Xavier et al. 2013).

Additionally, based on molecular weight, the following compounds might be also present: hamamelitannin (peak 5), myricetin 3-O-rhamnoside (peak 10), quercetin 3-glucoside (peak 10) and quercetin 3-glucoronide (peak 11) (Table 6, Figure 1). It is worth noting that all the phenolic compounds found have demonstrated antioxidant capacity (Romani et al. 1999, Moure et al. 2001).

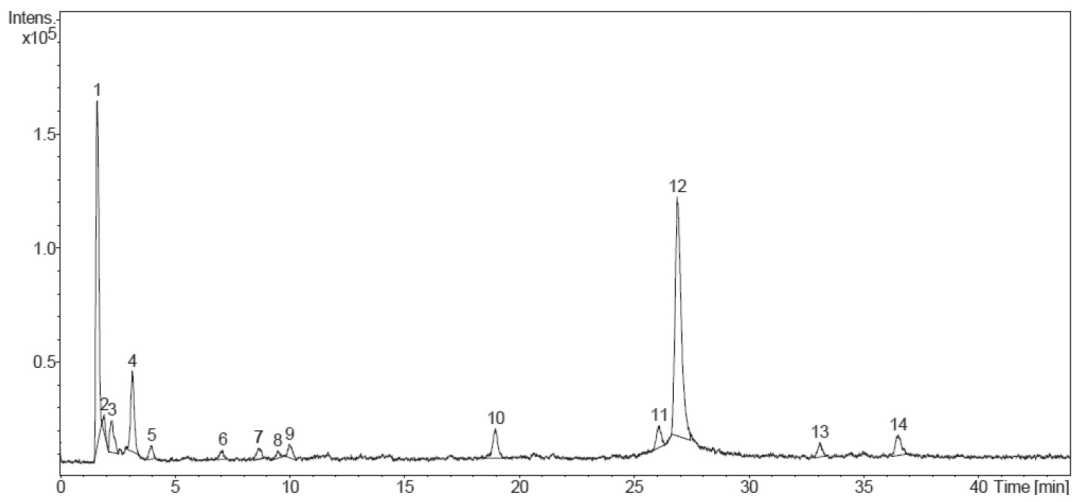

Figure 1. HPLC chromatogram of the Eucalyptus wood extract obtained with a PEG-sodium citrate ATPS under the selected conditions: TLL, 46,1\%; extraction time $90 \mathrm{~min}$; extraction temperature, $65^{\circ} \mathrm{C}$; settlement time, $1 \mathrm{~h}$.

Table 6. Phenolic compounds in the Eucalyptus wood extract obtained with a PEG-sodium citrate ATPS under the selected conditions: TLL, 46,1\%; extraction time 90 min; extraction temperature, $65^{\circ} \mathrm{C}$; settlement time, $1 \mathrm{~h}$.

\begin{tabular}{clcc}
\hline Peak & \multicolumn{1}{c}{ Compound } & {$[\mathrm{M}-\mathrm{H}]-(\mathrm{m} / \mathrm{z})$} & $\begin{array}{c}\text { Retention time } \\
(\mathrm{min})\end{array}$ \\
\hline 3 & Monogalloyl glucose & $331^{\mathrm{a}}$ & $2,1^{\mathrm{a}}$ \\
4 & (-)-Gallic Acid & $169^{\mathrm{a}}$ & $3^{\mathrm{a}}$ \\
12 & Ellagic Acid & $301^{\mathrm{a}}$ & $26,4^{\mathrm{a}}$ \\
13 & Quercetin 3-O-rhamnoside & $447^{\mathrm{a}}$ & $32,6^{\mathrm{a}}$ \\
5 & Hamamelitannin & $483^{\mathrm{b}}$ & $4,0^{\mathrm{b}}$ \\
10 & Myricetin 3- O-rhamnoside & $463^{\mathrm{b}}$ & $19,0^{\mathrm{b}}$ \\
10 & Quercetin 3-glucoside & $463^{\mathrm{b}}$ & $19,0^{\mathrm{b}}$ \\
11 & Quercetin 3-glucoronide & $477^{\mathrm{b}}$ & $26,1^{\mathrm{b}}$ \\
\hline \multicolumn{4}{c}{${ }^{\mathrm{a}}$ :according to standards; ${ }^{\mathrm{b}}:$ based on molecular weight }
\end{tabular}




\section{CONCLUSIONS}

The capacity of aqueous two-phase systems (water + polymer + salt) based on PEG 2000 and sodium citrate for the recovery of phenolic compounds from Eucalyptus wood wastes was demonstrated. It was found that phenolics had preference for the top PEG-rich phase and high partition coefficients were achieved. Phenolics recovery hardly depended on the phase settlement time, ATPS tie line length and extraction time. Total phenol yield increased with temperature, while selectivity was temperature-invariant. Analysis of the extracts by RP-HPLC-ESI-TOF confirmed the presence of phenolic compounds with potential antioxidant activity: monogalloyl glucose, (-)-gallic acid, ellagic acid and quercetin 3-O-rhamnoside.

\section{ACKNOWLEDGEMENTS}

The authors gratefully acknowledge the support of the company Aserpal S.A. that provided the Eucalyptus wood veneer trimmings used to carry out this research. The authors also want to thank the EMUNDUS17 project (Uruguay) for a grant awarded to Lucía Xavier.

\section{REFERENCES}

Aspé, E.; Fernández, K. 2011. Comparison of phenolic extracts obtained of Pinus radiata bark from pulp and paper industry and sawmill industry. Maderas. Ciencia y Tecnología 13(3): 243-252.

Aguilar, O.; Rito-Palomares, M. 2010. Aqueous two-phase systems strategies for the recovery and characterization of biological products from plants. Journal of the Science of Food and Agriculture 90: 1385-1392.

Albertsson, P. 1986. Partition of cell particles and macromolecules. J. Wiley and Sons, New York.

Benavides, J.; Rito-Palomares, M. 2008. Practical experiences from the development of aqueous twophase processes for the recovery of high value biological products. Journal of Chemical Technology and Biotechnology 83: 133-142.

Chavez-Santoscoy, A.; Benavides, J.; Vermaas, W.; Rito-Palomares, M. 2010. Application of aqueous two-phase systems for the potential extractive fermentation of cyanobacterial products. Chemical Engineering \& Technology 33: 177-182.

Chen, J.; Spear, S.K.; Huddleston, J.G.; Rogers, R.D. 2005. Polyethylene glycol and solutions of polyethylene glycol as green reaction media. Green Chemistry 7: 64-82.

Chethana, S.; Nayak, C.A.; Raghavarao, K.S.M.S. 2007. Aqueous two phase extraction for purification and concentration of betalains. Journal of Food Engineering 81: 679-687.

Conde, E.; Cadahia, E.; Garcia Vallejo, M.C.; Diez, R. 1996. Composición polifenólica de madera, corteza y hojas de Eucalyptus camaldulensis, E. globulus y E. rudis. Investigación Agraria Sistemas y Recursos Forestales 5:333-350.

Eyles, A.; Davies, N.W.; Mohammed, C. 2003. Wound wood formation in Eucalyptus globulus and Eucalyptus nitens: anatomy and chemistry. Canadian Journal of Forest Research 33: 2331-2339. 
Fernández-Agulló, A.; Pereira, E.; Freire, M.S.; Valentao, P.; Andrade, P.B.; González-Alvarez, J.; Pereira, J.A. 2013. Influence of solvent on the antioxidant and antimicrobial properties of walnut (Juglans regia L.) green husk extracts. Industrial Crops and Products 42:126-132.

Hasmann, F.A.; Santos, V.C.; Gurpilhares, D.B.; Pessoa-Junior, A.; Roberto, I.C. 2008. Aqueous two-phase extraction using thermoseparating copolymer: a new system for phenolic compounds removal from hemicelullosic hydrolysate. Journal of Chemical Technology and Biotechnology 83: 167-173.

Jokic, S.; Velic, D.; Bilic, M.; Bucic-Kojic, A.; Plannic, M.; Tomas, S. 2010. Modelling of the process of solid-liquid extraction of total polyphenols from soybeans. Czech Journal of Food Sciences 28(3): 206-212.

Khayati, G.; Daghbandan, A.;Gilvari, H.; Pheyz-Sani, N. 2011. Liquid-Liquid Equilibria of Aqueous Two-phase Systems Containing Polyethylene Glycol 4000 and Two Different Salts of Ammonium. Research Journal of Applied Sciences, Engineering and Technology 3(2): 96-98.

Moure, A. ; Cruz, J.M.; Franco, D.; Dominguez, J.M.; Sineiro, J.; Domínguez, H.; Nuñez, M.J.; Parajo, J.C. 2001. Natural antioxidants from residual sources. Food Chemistry 72:145-171.

Murugesan, T.; Perumalsamy, M. 2005. Liquid-Liquid Equilibria of Poly(ethylene glycol) $2000+$ Sodium Citrate + Water at $(25,30,35,40 \text { and } 45)^{\circ}$ C. Journal of Chemical and Engineering Data 50: 1392-1395.

Peng, Q.; Li, Z.; Li, Y. 1994. Thermodynamics of potassium hydrogen phosphatepotassium dihydrogen phosphate-polyethylene glycol aqueous two-phase systems. Fluid Phase Equilibria 95: 341-357.

Ramos, V.; Bocalandro, B.; Riquelme, S.; Sanhueza, V.; Aspé, E.; Roeckel, M.; Fernández, K. 2013. Effect of the bench scale extraction conditions on Pinus radiata bark extract yield, antioxidant properties and composition. Maderas. Ciencia y Tecnología 15(1): 31-44.

Ratanapongleka, K. 2010. Recovery of Biological Products in Aqueous Two Phase Systems. International Journal of Chemical Engineering and Applications 1:191-198.

Romani, A.; Pinelli, P.; Mulinacci, N.; Vincieri, F.F.; Tattini, M. 1999. Identification and Quantitation of Polyphenols in Leaves of Myrtus communis L. Chromatographia 49(1-2): 17-20.

Salic, A.; Tusek, A; Fabek, D.; Rukavina, I.; Zelic, B. 2011. Aqueous Two-Phase Extraction of Polyphenols Using a Microchannel System Process Optimization and Intensification. Food Technology and Biotechnology 49(4): 495-501.

Shen, S.; Chang, Z.; Liu, H. 2006. Three-liquid-phase extraction systems for separation of phenol and p-nitrophenol from wastewater. Separation and Purification Technology 49: 217-222.

Singleton, V.L.; Rossi, J.A. 1965. Colorimetry of total phenolics with phosphomolybdic - phosphotungstic acid reagents. American Journal of Enology and Viticulture 16: 144-158.

Vázquez, G.; Fontenla, E.; Santos, J.; Freire, M.S.; González-Álvarez, J.; Antorrena, G. 2008. Antioxidant activity and phenolic content of chestnut (Castanea sativa) shell and eucalyptus (Eucalyptus globulus) bark extracts. Industrial Crops and Products 28: 279-285.

Voros, N.; Proust, P.; Fredenslund, A. 1993. Liquid-liquid phase equilibria of aqueous two-phase systems containing salts and polyethylene glycol. Fluid Phase Equilibria 90: 33-353. 
Wang, H.; Dong, Y.; Xiu, Z. 2008. Microwave-assisted aqueous two-phase extraction of piceid, resveratrol and emodin from Polygonum cuspidatum by ethanol/ammonium sulphate systems. Biotechnology Letters 30:2079-2084.

Willauer, H.D.; Huddleston, J.G.; Li, M. ; Rogers, R.D. 2000. Investigation of aqueous biphasic systems for the separation of lignins from cellulose in the paper pulping process. Journal of Chromatography B 743: 127-135.

Wu, X.; Liang, L.; Zou, Y.; Zhao, T.; Zhao, J.; Li, F.; Yang, L. 2011. Aqueous two-phase extraction, identification and antioxidant activity of anthocyanins from mulberry (Morus atropurpurea Roxb.). Food Chemistry 129:443-453.

Xavier, L.; Freire, M.S; Vidal-Tato, I.; González-Álvarez, J. 2014. Aqueous two-phase systems for the extraction of phenolic compounds from eucalyptus (Eucalyptus globulus) wood industrial wastes. Journal of Chemical Technology and Biotechnology 89: 1772-1778. 